Article

\title{
Research on the Spatial Structure of County Greenway Network Based on Gravitation-Resistance Measurement-A Case Study of Ning'an in China
}

\author{
Xue Jiang and Tianyu Zhao * \\ School of Architecture, Harbin Institute of Technology, Key Laboratory of Cold Region Urban and Rural Human \\ Settlement Environment Science and Technology, Ministry of Industry and Information Technology, \\ Harbin 150000, China; 16b334018@hit.edu.cn \\ * Correspondence: HIT_tyzhao@hit.edu.cn; Tel.: +86-1307-432-1409
}

Received: 4 December 2019; Accepted: 10 February 2020; Published: 12 February 2020

\begin{abstract}
The ecological value, cultural value, economic value and industrial value of the county space, where a variety of human activities and natural ecological processes are carried out, act as the key elements considered in county spatial planning. However, there is a lack of carrying space for integrating these values in the actual Chinese county construction. In this article, the construction of a county greenway network is based on multiple needs, such as ecological protection, characteristic landscape, leisure and recreation. The ecological, cultural and economic values of resources are taken as the basis of identifying a greenway network. We establish the gravitation-resistance model to measure network flow based on the attraction and resistance between resources. In particular, by means of network flow analysis and the geographic information system (GIS), the resistance and gravity are assigned to the resources and landscapes, respectively. The attraction between elements is then measured using the gravitation-resistance model. The distribution of resources and the trend of integration are analyzed by the combination of the centrality of resources and the ratio of supply to demand. Based on the analysis results of network flow, the paper puts forward a strategy for developing a county greenway network, and improves the scientific evaluation of the spatial resource. It provides a new perspective for the construction of a county greenway network.
\end{abstract}

Keywords: greenway; compound greenway structure measurement; network structure evaluation; spatial modeling; gravitation-resistance measurement

\section{Introduction}

Green spaces have been an important part of the urban and rural environment, making a positive impact on public health by providing sports activities and social network promotion. Among all green spaces, greenways have been highly valued [1-3]. In their original definition, greenways are multi-functional linear spaces that connect natural ecological patches in order to avoid the fragmentation of ecological patches and maintain the balance between the natural and artificial environments [4]. According to the concept put forward by Jack Ahern, as a linear network land-use system, a greenway's functional diversity (ecology, entertainment, culture, aesthetics) determines that the construction is the result of multiple resources combination [5]. While economic growth improves citizens' living standards, potential ecological patches and resources networks can be disturbed by economic activities like disorderly construction [6]. Therefore, in the construction of public spaces, the greenway, as an important network system connecting ecological and landscape functions, meets the needs of landscape upgrading and resources reorganization to a certain extent and plays an essential role in multi-functional planning in most areas $[7,8]$. 
During the current rapid development of Chinese urban and rural areas, the county has gradually become the space for urban infrastructure and non-environment-friendly industries [9,10]. Counties are made up of towns and villages in China and are the basic administrative jurisdiction unit. They also constitute the most widely distributed, numerous and basic residential area type in the urban system of China [10]. The total area of county-level administrative jurisdiction in China accounts for about $80 \%$ of the land area, and the total population accounts for about $70 \%$ of the national population $[10,11]$. It concentrates a large number of ecological, cultural and landscape resources, and plays an irreplaceable role in China's ecological situation [10,12]. Therefore, China's county green space planning involves many types of spatial resources and complex population characteristics. However, its actual construction still remains a "greenway-like" form [12]. In addition to economic reasons, the lack of measurement methods and theoretical models of composite resources in greenway network planning is one of the most important reasons for this. To enhance the vitality of the greenway in an all-around way and also realize its complex functions, it is particularly important to measure the network structure of the greenway and to integrate the values of ecology, production and living factors in the planning $[13,14]$.

Relevant research shows that a greenway is multifunctional in addition to the diversity of its types and the richness of its forms. In this study, a greenway network refers to a compound green system that glues together natural factors, artificial factors and social factors $[15,16]$. It is an all-around construction that meets the overall development of the economic industry, the social environment and the ecosystem, hence being characterized by comprehensiveness, economy and sociality $[17,18]$. The diversity in construction of a county greenway network refers to the consideration of a variety of natural conditions and cultural resources such as complex cultural sites, folk customs, related construction land (e.g., village and town residential areas) and industrial resources (agriculture, forestry, tourism, transportation resources, etc.) that can increase its economic value [19]. The weight of different functions is generally obtained by the method of the Delphi system [20]. In this method, experts in related fields are invited to score the functions involved in related research to obtain the weight of each resource [21]. With such diversity, comprehensive benefits can be multiplied by the complex ecological, cultural and economic values [22]. Furthermore, this value promotion comes from people's affirmation of the rural environment, as well as the protection and utilization of secondary cultural and tourism resources. There are three ways to achieve the value promotion by function compounding [21-23]: (1) Functional diversification: controlling the scale of resource land or function unit in a small range, and combining relevant research with the Delphi expert system method to determine the compounding relationship and composite intensity coefficients of different resource types. (2) Space sharing: On the basis of the main functions determined by the nature of land use, the spatial composition of the greenway functions can generate a public space-sharing mode without being restricted to one land use type. (3) Interlacing: flexible time and space in the use of greenway space, making possible the alternation among landscape, ecology, commerce, recreation, humanities, transportation and municipal functions on the same land (the main functions of greenways involved in this study), and thus improving the composite utilization rate of a single space and the conversion rate of multiple values.

In previous studies, network structure was the essential content that greenway planning was concerned with [22,24]. Generally, quantitative evaluations on the structure focus on the relationship between point-line elements in the network, and reveal the importance and validity of the network structure according to graph theory, probability theory and more $[24,25]$. Furthermore, a network with multi-value coupling has a complex structure and complicated elements. This kind of complex network forms the power to promote the mutual transformation of integrated functions, which is called the integrated network function flow [26,27]. For a network dominated by an ecological function, landscape centrality and its measurement were put forward to identify key elements and to build a coherent ecological network [28]. However, the carrying capacity and functional flow of resources are less discussed, and the network function flow is mostly defined based on the number of 
people or amount of traffic [29]. From the perspective of landscape ecology, the least-cost distance model and landscape connectivity theory are usually applied to solve the related problems $[30,31]$. In the least-cost distance model, the existing green space patches with suitable ecological functions constitute the network source points, forming the ecological function flow diffusion and maintaining the ecosystem balance [32]. The basic definition of the widely used landscape connectivity theory was mainly proposed by Taylor et al. Landscape connectivity is the degree of promoting or hindering the movement of organisms between source patches in a certain ecological process, forming a network in the mode of resource nodes and corridors [33]. In the process of landscape connection, landscape resistance refers to the influence of elements on ecological flow rate, and the resistance increases with the increase of the frequency of crossing various landscape boundaries [33,34]. It can be seen that the theory of landscape connectivity is to explore the organic relationship between similar patches or heterogeneous patches in the process of function and ecology [34]. This kind of organic connection may be the direct exchange of material and energy between the elements or the species exchange between biological groups [35].

However, the functional flow and its spatial structure in this study involve not only ecological function and value. On the basis of landscape connectivity, we find multi-functional and multi-resource networks can be explained directly and clearly in theory and space by using a gravity model [36-38]. In this study, the generation of the network and function flow are calculated by the gravity and resistance between resources. This is a calculation similar to the gravitational model, which can reveal the relationship between elements directly and clearly using the concept of network flow [39]. The gravity model can be regarded as a bridge connecting physical science and geographical science. Geographers strive to use the law of gravitation of nature to analyze and study the relationship between regions [40]. According to the gravity model, each research object has a certain mass and is usually treated as a point of mass, which may be the center in the geometric sense or the center in another specific sense, such as regional politics, culture, economy or population center [41]. The gravity model also naturally assumes that there is a mutual attraction between any two points, which can be used to study the relationship and network flow between the objects; the intensity of this attraction is inversely proportional to the distance between the two measured points [42].

In light of the previous research on the subject of the greenway, the current study aims to propose a new measurement method of a greenway network structure under the influence of multiple elements, and to explain the application and analyzing process of the measurement through the case study of Ning'an. In this study, the resource flow between the resource nodes of a greenway is taken as the mutual attraction. The method of networked organization of resources is applicable to county areas with rich resources and a controllable scale; thus it is feasible to do this research at the county scale. This method has been implemented on the case study of Ning'an. The main concept is the structural organization of a county greenway network. The organization of the greenway network needs the combination of multiple resources and functions, so it is different from scenic byways used by buses full of tourists. First of all, we conducted a wide survey of all resources in Ning'an to select the suitable resources for the greenway network; then the structure was measured using network structure abstract analysis, and the scheme of the structure reconstruction was proposed; the emphasis of this method is the realization of the structure reconstruction, which was illustrated by the planning of a greenway line location using GIS.

\section{Measurement and Analysis Method of Greenway Network Flow}

\subsection{Measuring Steps and Framework}

The flow measurement of a greenway network can be realized using a gravity model. Through the structural evaluation and analysis of the flow measurement of the gravity model and the improvement of the least-cost distance formula, each path is assigned with a flow for the network measurement. The measurement and analysis can be concluded in the following four steps (see Figure 1). Firstly, based 
on the multi-value coupling of ecology, recreation and resource coordination functions, the related elements including cultural resources protection, ecological conservation, tourism value promotion and land comprehensive utilization are selected to identify and extract resources. These elements are the resource points of the network flow analysis and the basis of the greenway network reconstruction. Secondly, landscape resistance and gravity are assigned to the resources and the gravitation-resistance model is adopted to measure the attractiveness of the elements. Thirdly, given the centrality of the resource landscape and the supply-to-demand ratio, we analyze the distribution and the use situation of the corridor function flow. Finally, the results of the structure flow analysis guide us to propose the structural optimization and ecological, cultural and economic multi-planning strategies to enhance the overall planning and optimization of county resources.

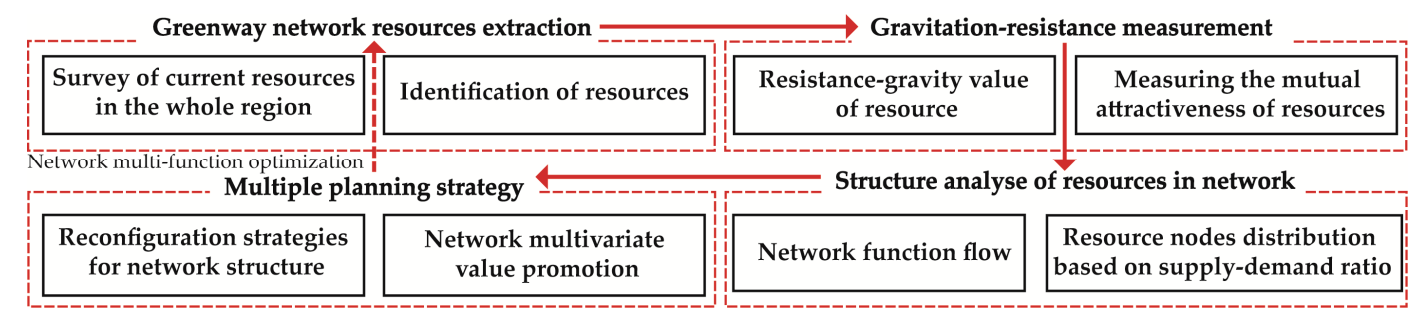

Figure 1. Measurement and analysis route.

\subsection{Gravitation-Resistance Model Construction}

(1) Greenway network resources extraction

- Compound relationship and weight of resources

In the process of building the greenway network measurement model, it is necessary to clarify the composite weights of various resources because of the multi-function involved in the measurement. As for the function of the compound greenway, the compound features proposed in this study are determined by the characteristics of the studied area. Combined with the researches of spatial resources types in the county, the key composite resources include natural resources, economic and industrial resources, human resources, transportation land resources, village and town settlements and other recreational resources [43-45]. The function composite weight of the greenway network composite is determined according to the combination of different functions through relevant research results and the Delphi expert system method. The weights were assessed by a group of fifteen experts consisting of four professors specialized in landscape analysis as well as in techniques and methods for greenway spatial planning, and eleven landscape architects specialized in designing public green areas. Specific composite weights are illustrated in Figure 2.

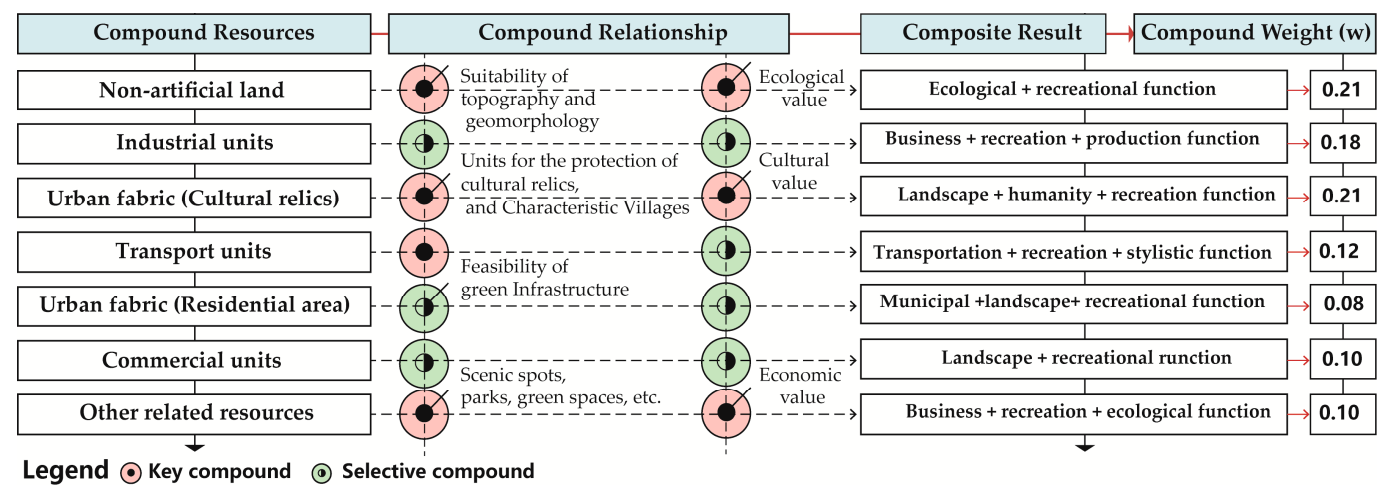

Figure 2. Compound relationship and weight of greenway network resource function.

- Identification of resources from the perspective of pluralism 
To start with, we first identified whether the resource elements of the greenway network have ecological value, cultural value and economic value. The ecological function of the greenway was evaluated based on the principle of reducing the negative impact of artificial construction on the ecological environment along the way. The ecological function was considered the center of the complex greenway network, and the resources with cultural and economic value suitable for joining the greenway network were screened. In the consideration of the humanistic value of the greenway resources, we focused on the service ability of service facilities, the influence ability of the humanistic resources and the scale and influence degree of the recreational resources. With regard to economic value, it is essential to pay attention to the economic benefits of resources, industrial types and scale. In the resource identification and organization, the multi-functional attribute of the greenway, which differs from that of a traffic road or scenic road, was emphasized.

The basic investigation of ecological resources, human resources and economic resources stands as the foundation of the evaluation of resource ecological value, human value and economic value [46]. The resource extraction standard was used to evaluate the value of resources and extract the resource elements that are key factors of greenway network. Under the relevant evaluation criteria of Landscape Ecological Construction (released by the Ministry of Housing and Urban-Rural Construction in 2012) in China, and the Guidelines for Greenway Planning and Design (released by the Ministry of Housing and Urban-Rural Construction in 2016) [47], we constructed the extraction index system (see Table 1) with the scores corresponding to indicators in the evaluation system. Through field investigation and image and data analysis, we studied the current situation of resources in the whole region, including land use, natural environment, industrial development, transportation resources and related planning. Ecological resource value, cultural value, and economic value were then coupled. The resources of each indicator were scored according to the actual situation of the county resources. The resources whose comprehensive score exceeded 60 were regarded as the structural measurement objects.

Table 1. Greenway network resources extraction standard.

\begin{tabular}{|c|c|c|c|}
\hline Resource Value & $\begin{array}{c}\text { Coupling Direction } \\
\text { of Resource }\end{array}$ & Extraction Index & Score \\
\hline \multirow{10}{*}{ Ecological Value } & \multirow{3}{*}{$\begin{array}{l}\text { Green Quantity } \\
\text { Planning }\end{array}$} & A1: Net loss rate of wetland woodland & 1 \\
\hline & & A2: Forest coverage & 3 \\
\hline & & A3: Per capita area of public green space & 7 \\
\hline & \multirow{3}{*}{ Structure Planning } & A4: Greenway density & 3 \\
\hline & & A5: Greenway connectivity & 5 \\
\hline & & A6: Greenway accessibility & 9 \\
\hline & \multirow{2}{*}{$\begin{array}{c}\text { Restoration of } \\
\text { Ecological Structure }\end{array}$} & A7: Species diversity & 3 \\
\hline & & A8: Proportion of native plant species & 1 \\
\hline & \multirow{2}{*}{$\begin{array}{c}\text { Environmental } \\
\text { Benefit }\end{array}$} & A9: Carbon reduction & 1 \\
\hline & & A10: Environmental protection investment index & 3 \\
\hline \multirow{11}{*}{ Cultural Value } & \multirow{5}{*}{ Service Facilities } & A11: Service radius of facilities & 5 \\
\hline & & A12: Coverage rate of noise achievement zone & 1 \\
\hline & & A13: Harmless treatment rate of domestic waste & 1 \\
\hline & & A14: Standard emission rate of industrial pollution & 1 \\
\hline & & A15: Proportion of administrative village for domestic sewage treatment & 5 \\
\hline & \multirow{4}{*}{$\begin{array}{l}\text { Human Resources } \\
\text { Planning }\end{array}$} & A16: Age of construction & 7 \\
\hline & & A17: Historical position & 5 \\
\hline & & A18: Popularity & 7 \\
\hline & & A19: Integrity & 1 \\
\hline & \multirow{2}{*}{$\begin{array}{c}\text { Recreational } \\
\text { Resources Planning }\end{array}$} & A20: Number of recreational projects & 3 \\
\hline & & A21: Convenience of recreational resources & 5 \\
\hline \multirow{4}{*}{ Economic Value } & \multirow{2}{*}{$\begin{array}{c}\text { Economic } \\
\text { Performance }\end{array}$} & A22: Benefits of tourism resources & 7 \\
\hline & & A23: Employment-driven benefits & 9 \\
\hline & \multirow{2}{*}{$\begin{array}{c}\text { Industry Type } \\
\text { and Scale }\end{array}$} & A24: Industrial service radius & 3 \\
\hline & & A25: Supporting function of industry & 4 \\
\hline
\end{tabular}


(2) Gravitation-resistance measurement model

Generally, gravity models have been proposed by relevant researches via replacing the parameters, mass and distance in the original model by other factors [48]. At present, the gravity model has been widely used in the research and analysis of economic geography and regional geography, especially in the field of new economic geography. The gravity model has become the core tool for analyzing the spatial interaction of different regions [49]. The gravity model considers that each research object has a certain quality, and the interaction between the research objects can be seen as a focus on a certain "point", which can be the center in a geometric sense, or other specific meaning centers, such as regional political, cultural, economic and population centers. When the research object is abstracted as a point in space, different points have mutual attraction, and the two points attract each other to make the research object connected with each other [50]. In order to measure mutual attraction between patches, the mass and distance parameters in the gravity model are replaced according to the greenway network. Therefore, the measurement model can be constructed by determining the landscape resistance and gravitational value among the elements and improving the gravitational formula. Afterwards, resource centrality and a supply-demand ratio are applied to the analysis on the needs of network planning.

\section{- Gravitation-resistance value of resources}

The landscape resistance of resources is the influence of resources on the energy flow rate of a composite network. In this study, the resistance content is expanded from a single ecological field to all kinds of resources in the whole region in order to reflect the mutual influence of resources and the supporting capacity of the whole network. By taking the landscape type as a resistance factor and referring to the existing research results [51-53], the landscape resistance coefficient $\mathrm{f}$ can be determined. Starting from the type of composite resources, considering the interference of ecological, humanistic, industrial and recreational factors in the diffusion of energy flow in the network [54], the gravitational value $\mathrm{R}$ (see Table 2) of resources can be calculated from the composite weight coefficient under certain resource extraction criteria (decided according to Figure 1 and Table 1). A stronger composite function implies a higher gravitational value of resources.

Table 2. Resistance coefficient and gravitation value per unit of different resources ${ }^{1 .}$

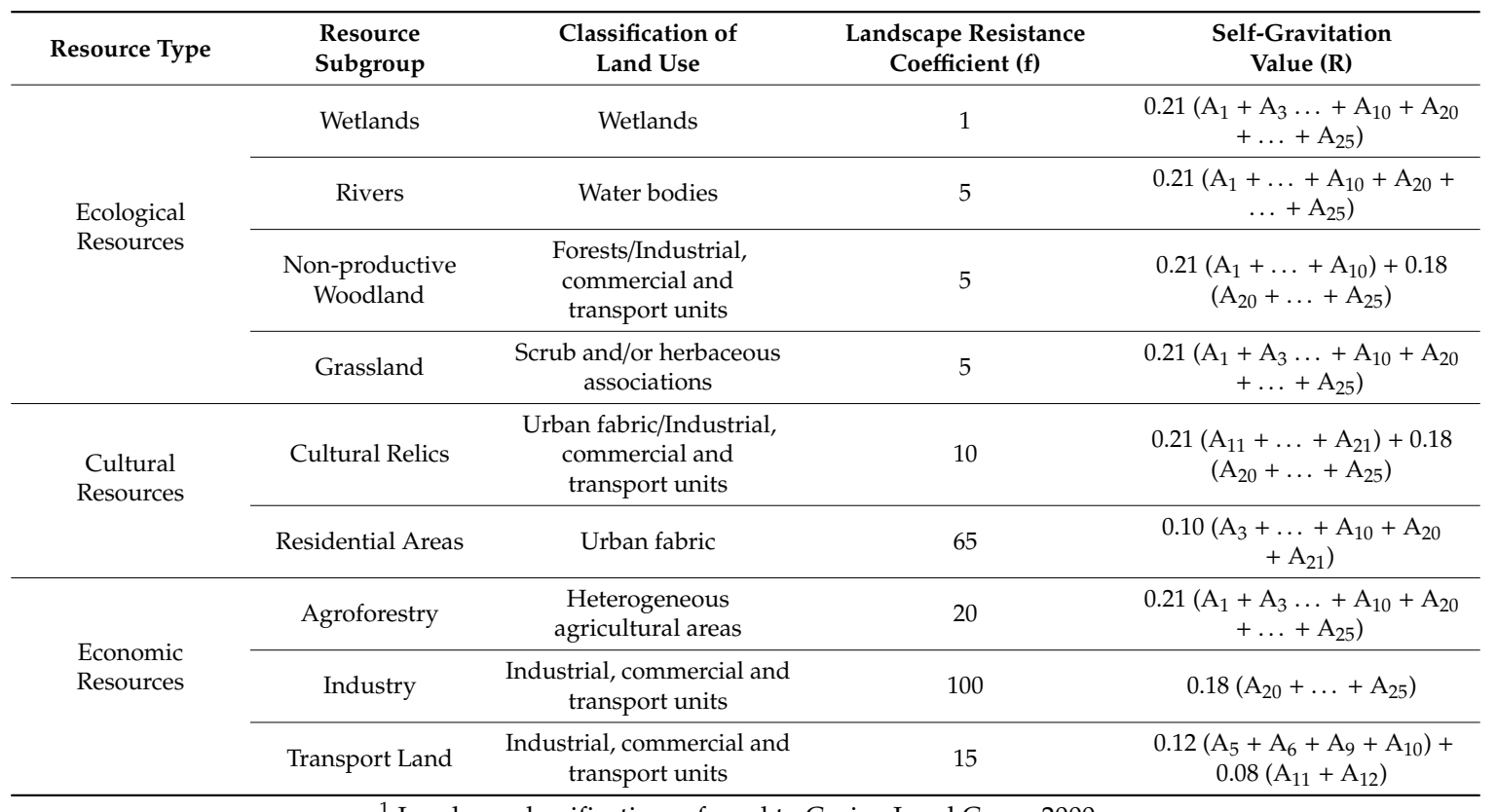

${ }^{1}$ Land use classification referred to Corine Land Cover 2000. 
The last step in presenting resistance-gravity value involves transferring the evaluation of the gravity-resistance measurement to the GIS environment to improve the construction application of the model. Firstly, the data is digitized and transformed into the GIS environment. Specifically, according to the functional flow calculation between node resources using a cell size $(90 \times 90 \mathrm{~m})$ to perform the rasterization, the grating of gravity-resistance values is realized. Finally, the function raster calculator is applied to generate functional flow distribution maps. After data standardization, corridors with a flow above 40 are considered as high-function flow corridors; corridors with a flow between 30 and 40 are considered as medium function flow corridors; corridors with a flow between 10 and 30 are regarded as low function flow corridors. For node resources, flow determines the centrality and supply-demand ratio.

- Measuring the mutual attractiveness of resources

The "mass" is replaced by the node's own gravitational value, and the "distance" is replaced by the resource resistance distance, a function of the actual distance between nodes and their own resistance coefficient. The improved gravitational formula is expressed as follows:

$$
F_{i j}=R_{i} R_{j} / L_{\text {min }}=R_{i} R_{j} /\left(D_{i j} \times f_{i} \times f_{j}\right), i=1 \ldots \mathrm{N}, j=1 \ldots \mathrm{N}
$$

$F_{i j}$ denotes the attraction between node $i$ and $j . R i$ and $R j$ denote the attraction value of nodes $i$ and $j$, respectively. $L_{\min }$ denotes the distance of landscape resistance between nodes $i$ and $j . D_{i j}$ denotes the distance between nodes $i$ and $j$. According to this, the flow matrix of attractiveness for the $N$ nodes in the network is generated.

- Node resources function centrality based on flow measurement

The measurement of greenway nodes is mostly based on a center degree under the influence of node connectivity and the Euclidean distance between nodes [55], and the attributes and functions of resources are not fully considered. The analysis of landscape function centrality based on network flow measurement and the measurement of mutual attraction between resources can help to clarify the characteristics of resource nodes and the use of different age groups by replacing the value of spatial distance in the original centrality evaluation with the restriction of characteristic conditions.

$$
C_{i}=\frac{\sum_{j=1 ; j \neq i}^{N} F_{i j}}{N-1}
$$

In this formula, $C_{i}$ is the function centrality of the first resource node. $N$ is the number of nodes. $F_{i j}$ is the mutual attraction between nodes $i$ and $j$.

- Supply-demand ratio of network resources based on flow measurement.

Inter-resource attractiveness is expressed in terms of inter-resource flow. The actual problems of county space, including the selection of complex accessible resource nodes by human flow and the utilization of resources in working days and rest days, can be analyzed by using of the supply-demand ratio of nodes [56]. The node's supply capacity is expressed by the ratio of its own gravity to the gravity sum of other nodes in the network. The study of the supply-demand ratio can be grouped by age, land type and traffic peaks. The supply-demand ratio $L_{i}$ of the node $i$ is defined as follows:

$$
L_{i}=S_{i} / D_{i}=R_{i} / \sum_{i=1}^{n}\left(\mathrm{~F}_{1 \mathrm{n}}+\mathrm{F}_{2 \mathrm{n}}+\ldots \mathrm{F}_{(\mathrm{n}-1) \mathrm{n}}+\mathrm{F}_{\mathrm{n} 1}+\mathrm{F}_{\mathrm{n} 2}+\ldots+\mathrm{F}_{\mathrm{n}(\mathrm{n}-1)}\right)
$$

where $S_{i}$ is the supply capacity of node $i$, and $D_{i}$ is the demand of node $i$. By using the natural breakpoint method of GIS, the resource nodes with different centrality and supply-demand ratio are divided into five grades. The higher the grade, the higher the value of the node is. 


\section{Case Study: Measurement and Planning Strategy in the Ning'an Greenway}

\subsection{Case Selection and Survey of Current Resources}

Ning'an is a county-level city in the main ecological landscape and tourism development zone of Mudanjiang City, Heilongjiang Province. It comprises important agricultural and forestry industrial nodes in the Mudanjiang Economic Development Zone (see Figure 3e). It is also well known for its unique volcanic landforms and ecological resources in the Jingpo Lake Scenic Area (see Figure 3e). There also exist a remarkable folk customs culture and ancient sites.

Under the ArcGIS 10.0 platform (Environmental Systems Research Institute, Redlands, CA, USA), referring to the Corine Land Cover 2000, the land use image (2017) of Ning'an is used as the basis for analysis (see Figure 3b). In terms of the development and combination background of resources, relevant planning is taken as guidelines, such as the 2011-2030 Master Plan of Ning'an city (by the Ning' an municipal government), the 2006-2020 Master Plan of Land Use of Ning'an city (by the natural resources department of Ning'an government) etc. In terms of land distribution, the structure of land use in Ning'an is still dominated by cultivated and forest land, accounting for more than $90 \%$ of the total area. There are 15 key agricultural and forest resource nodes (see Figure 3d). In the development of recreation and tourism, there are 60 tourism resource nodes in Ning'an, which include both natural and cultural ones. In other words, green space and the basic conditions of resources have certain advantages for using as greenways in Ning'an. However, according to the survey of 465 local people (500 questionnaires about greenway utilization rate), the utilization rate of greenway resources is less than $60 \%$. Therefore, cultivated by its rich resources of nature, culture, agriculture, forestry industry, tourism industry etc., Ning'an has witnessed the formation of its greenway network (see Figure 3b-f), which offers important ecological services and environmental regulation functions in the south of Heilongjiang Province. In general, the planning of the greenway network in Ning'an is facing a critical stage of improving its utilization rate by combining multiple resources. The multiple-resource coordination and value combination of the greenway network are of great significance to the county itself, as well as to the ecological environment optimization and industrial value promotion in the south of Heilongiiang Province.

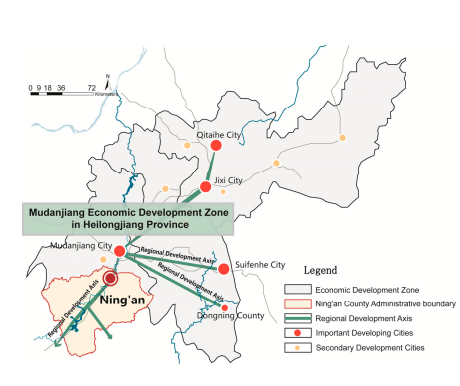

(a)

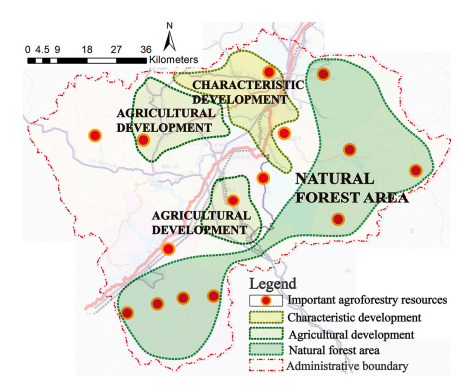

(d)

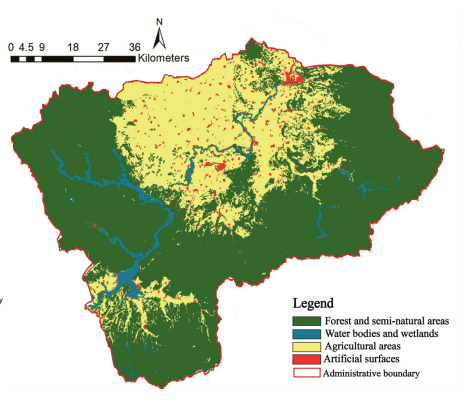

(b)

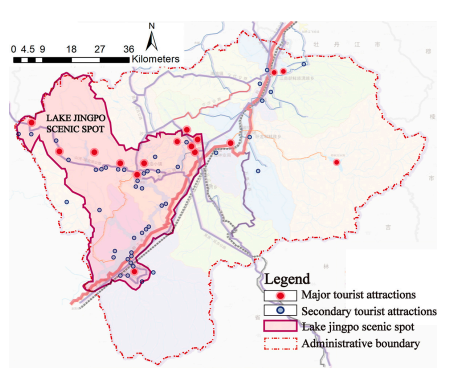

(e)

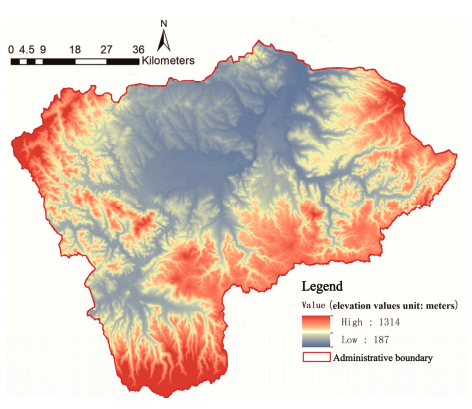

(c)

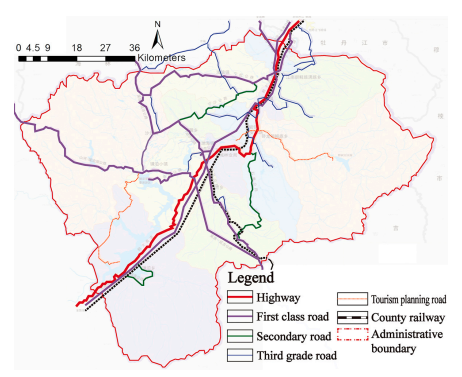

(f)

Figure 3. Current situation analysis of county areas in Ning'an. (a) Location; (b) land use; (c) elevation status; (d) distribution of agroforestry; (e) distribution of tourism; (f) distribution of traffic. 


\subsection{Network Structure Recognition and Analysis}

\subsubsection{Network Structure Recognition}

Elements are identified and extracted according to the recognition model, the characteristics of integrated ecological background resources and the coupling potential [57]. The weights of indexed elements were assigned by experts to a scale referring to the corresponding standards of national and regional indicators, along with the actual situation of Ning'an. A total of 23 nodes and 31 corridors were identified to form a three-grade network structure (see Figure 4). The first-grade network structure is the network skeleton that links important transportation resources, rivers, industries, scenic spots and other resources together, connecting the main residential areas, industrial parks and the Jingbo Lake scenic spots from the north to the south. It also connects the Xiaobeihu scenic spot in the west and extends to the Huashuchuan Reservoir in the east. The second-grade network structure links the fringe elements and improves the connection degree of the first-grade structure, showing a trend of expansion to the county fringe areas. However, the integrity and connectivity of the secondary network itself are weak. The third-grade network mainly contains the location-level links, which yield a more intensive network layout in the east and south.

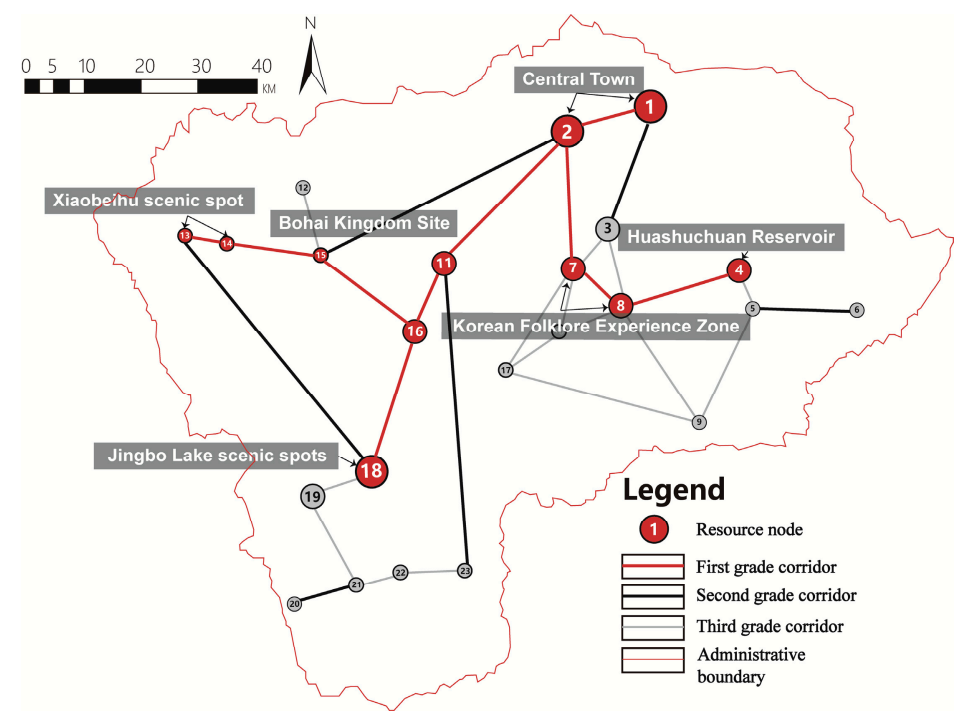

Figure 4. Greenway abstract network hierarchy.

\subsubsection{Network Structure Analysis}

(1) Network function flow

On the basis of network identification, the cost matrix of mutual attractive capability among nodes (see Table 3) is obtained according to Formula (1) and the actual situations of resource points. 
Table 3. Cost matrix of mutual attractive capability among nodes.

\begin{tabular}{ccccccc}
\hline $\mathbf{1}$ & $\mathbf{2}$ & $\mathbf{3}$ & $\mathbf{2 1}$ & $\mathbf{2 2}$ & $\mathbf{2 3}$ & Serial Number \\
\hline $\mathrm{F}_{11}=0$ & $\mathrm{~F}_{21}=0.13$ & $\mathrm{~F}_{31}=0.22$ & $\mathrm{~F}_{211}=5.91$ & $\mathrm{~F}_{221}=5.71$ & $\mathrm{~F}_{231}=4.59$ & 1 \\
\hline $\mathrm{F}_{12}=0.13$ & $\mathrm{~F}_{22}=0$ & $\mathrm{~F}_{32}=0.53$ & $\mathrm{~F}_{212}=13.16$ & $\mathrm{~F}_{222}=14.67$ & $\mathrm{~F}_{232}=9.77$ & 2 \\
\hline $\mathrm{F}_{13}=0.22$ & $\mathrm{~F}_{23}=0.22$ & $\mathrm{~F}_{33}=0$ & $\mathrm{~F}_{213}=11.52$ & $\mathrm{~F}_{223}=12.84$ & $\mathrm{~F}_{233}=14.49$ & 3 \\
\hline & & & & & \\
\hline $\mathrm{F}_{121}=5.91$ & $\mathrm{~F}_{221}=13.16$ & $\mathrm{~F}_{321}=11.52$ & $\mathrm{~F}_{2121}=0$ & $\mathrm{~F}_{2221}=0.07$ & $\mathrm{~F}_{2321}=0.41$ & 21 \\
\hline $\mathrm{F}_{122}=5.71$ & $\mathrm{~F}_{222}=14.67$ & $\mathrm{~F}_{322}=12.84$ & $\mathrm{~F}_{2122}=0.07$ & $\mathrm{~F}_{2222}=0$ & $\mathrm{~F}_{2322}=0.14$ & 22 \\
\hline $\mathrm{F}_{123}=0$ & $\mathrm{~F}_{223}=9.77$ & $\mathrm{~F}_{323}=14.49$ & $\mathrm{~F}_{2123}=0.41$ & $\mathrm{~F}_{2223}=0.14$ & $\mathrm{~F}_{2323}=0$ & 23 \\
\hline
\end{tabular}

The network corridors are divided into three grades by using the natural breakpoint method of GIS, based on the mutual attraction of resource nodes (see Figure 5). From the overall distribution of flow, there is a positive correlation between the distributions of corridors. However, it also leads to the uneven distribution of resources, resulting in low resource utilization and limited development in the south and southeast. High-function flow corridors are relatively concentrated between the county center and Jingpo Scenic Area along the Mudanjiang River. In these areas, cultural tourism resources are densely distributed and the corridor utilization rate is relatively high. Medium-function flow corridors are mostly distributed in the central Korean Folklore Experience Zone. The functional flow is generally at low grades in eastern corridors, mountain woodlands and southern areas.

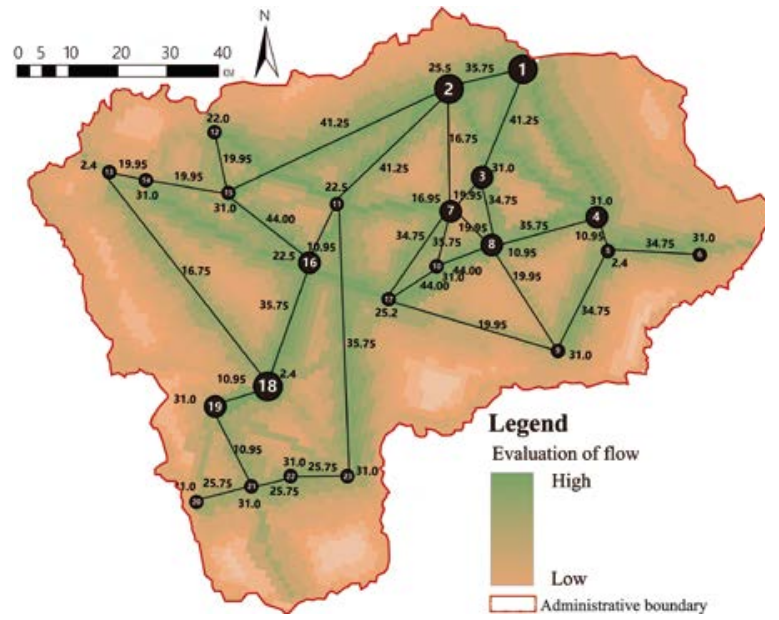

(a)

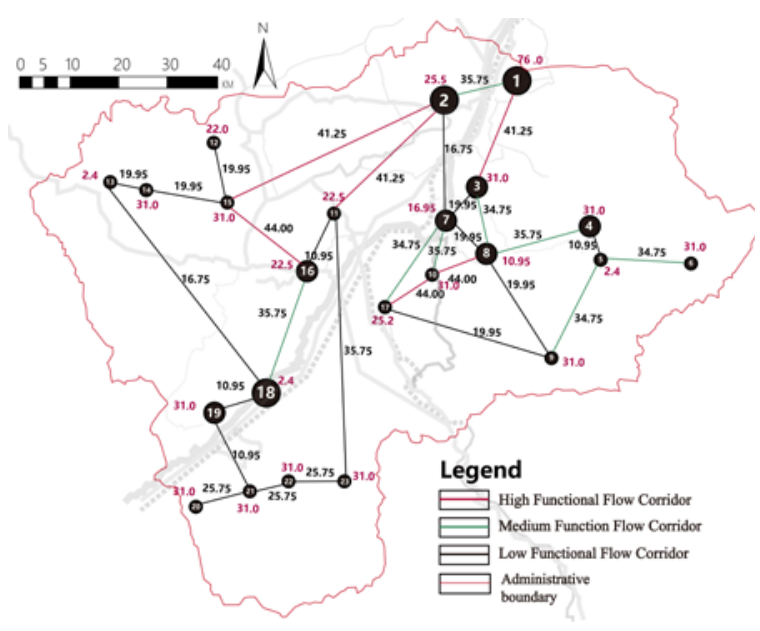

(b)

Figure 5. Calculated results of county corridor function flow. (a) Structural calculation results; (b) flow classification.

Network flow is affected to some extent by the difference in the recreational flat peak (see Figure 6). In the peak period, because of low road impedance and strong accessibility, the function flow of the greenway around main roads is relatively large. The resources of scenic spots in the west and southwest are relatively concentrated, and the corridor flow between the central area of the county and scenic spots is largest when the node flow is equal. Compared with the flat peak, the flow of resource points, which are more marginal in peak period, decreases, while the flow of corridors near the county center and scenic spots increases. The corridors with higher functional flow levels decrease and become relatively concentrated due to the increase of road impedance during peak period, and the influence range in scenic spots and surrounding areas also decreases. 


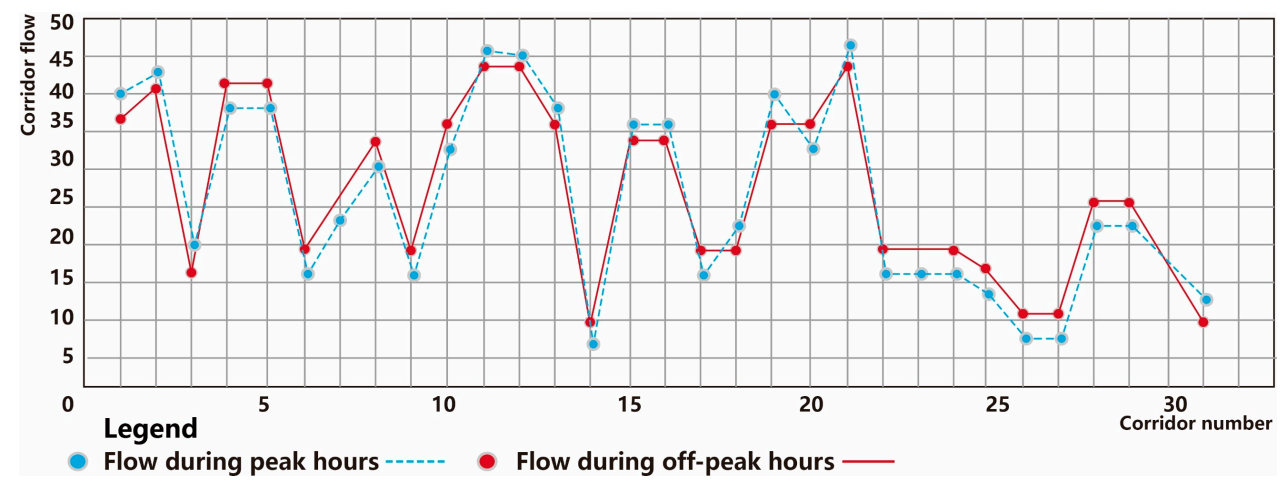

Figure 6. Contrastive analysis of corridor flow at peak hours and off-peak hours.

The scale of recreational functional land is large and landscape resistance between resources is relatively small in Ning'an. The resource nodes with higher landscape function centrality are mainly distributed in the Jingpo Lake Scenic Area, the main road and the Bohai Kingdom Site (see Figure 7a), which has a great impact on the county resource function transmission. At the same time, regional high-intensity nodes have appeared in limited areas, such as the Huashuchuan Reservoir and the Korean Folklore Experience Zone, but the development and compounding degree of these nodes is relatively low, and the diffusion mode of the facilitating peripheral functional flow has not yet been formed.

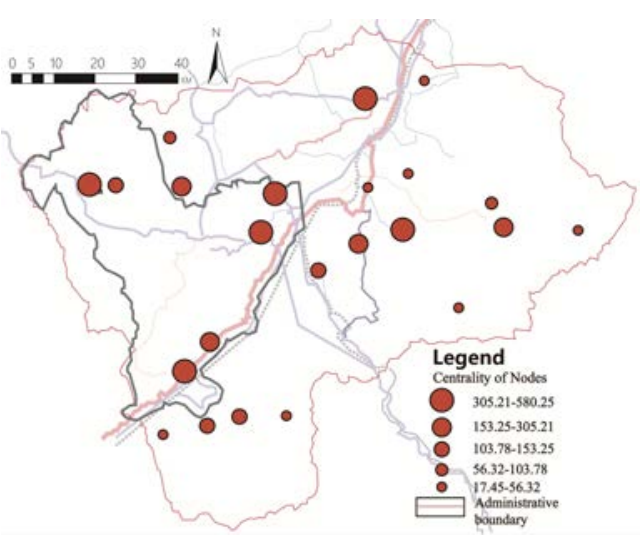

(a)

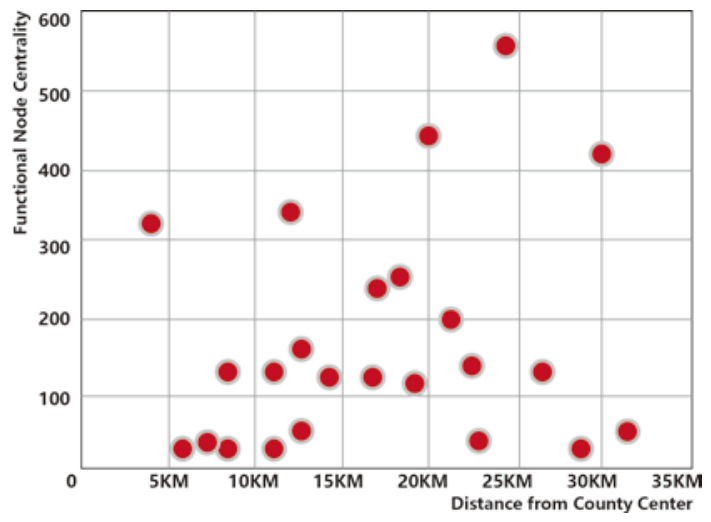

(b)

Figure 7. Analysis of node resource centrality. (a) Distribution; (b) distance from the central town.

The relationship between node resources centrality and distance from the county center shows an upward trend and then a downward one. Medium and high centrality nodes mainly distribute in the radius range from $15 \mathrm{~km}$ to $25 \mathrm{~km}$. The number of nodes within the radius of $10 \mathrm{~km}$ from the central city is relatively small and only 2/7 of them distribute in high and middle centralities (see Figure 7b).

(2) Resource nodes distribution based on a supply-demand ratio

- Analysis of resource supply-demand ratio under age difference.

People of different ages have distinct expectations from the greenway space and function in Ning'an. Considering the aging population of Ning'an, the senior citizens are greatly affected by their physical strength and external climate conditions, and therefore they have higher demand for the accessibility of the greenway activity space. On the other hand, the main outdoor activities of these elders in Ning'an during the day are carried out in squares, grasslands, parks, etc., which are close to the greenway space, so the demand for the daily recreational function of the greenway is also relatively high. Overall, the areas with high supply and demand of adult daily node resources are mainly 
located in the county center, in the Jingpo Scenic Area and in its surrounding areas (see Figure 8a). The resource nodes with a supply-demand ratio above 35.21 are mainly distributed along the national highway, forming a more adequate area for daily leisure supply and demand. The resource nodes with a supply-demand ratio above 59.43 have a higher degree of coupling of ecological, economic and human values, which are concentrated in the western areas with dense human resources and abundant natural resources, such as the Jingbo Lake Scenic Area and the Bohai Kingdom Site. Because of the low population base of the elderly, the supply-demand ratio of resource nodes is generally higher in the scope of their action, and quite different in the county center, scenic spots and other parts. The resource nodes in the county center have relatively sufficient supply capacity for the daily recreation and leisure for the elderly (see Figure 8b). At the same time, although large-scale resource nodes have a high functional flow, the daily needs of the elderly are limited by travel time, traffic friendliness and other aspects. The utilization rate of large-scale recreational resource sites remains relatively low, such as the Jingbo Lake and the Bohai Kingdom Site.

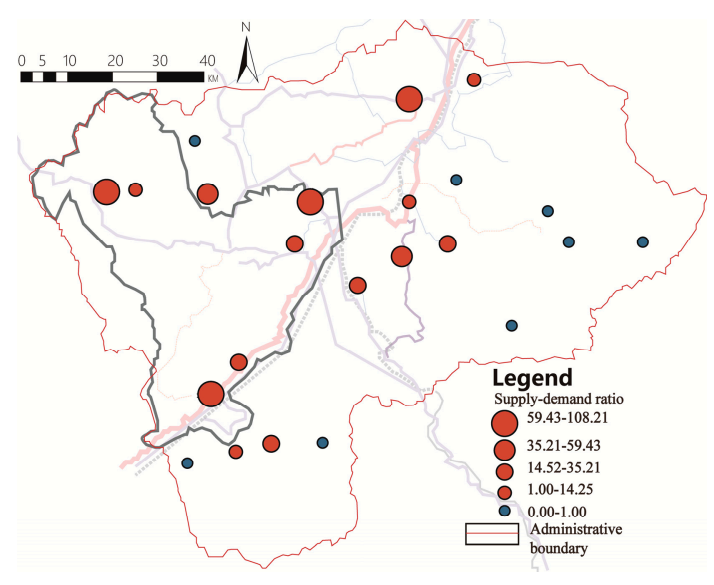

(a)

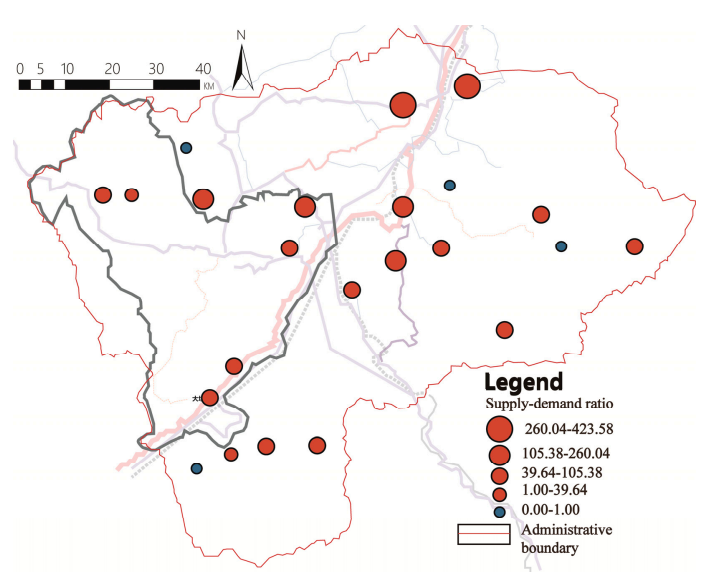

(b)

Figure 8. Supply-demand ratio of daily node resources. (a) Adults; (b) the elderly.

- Supply-demand ratio of recreational resources in the peak and off-peak periods.

To some extent, the supply and demand of recreational resources are greatly affected by holidays. The supply-demand ratio of daily resource nodes is less affected by the distance from the county center area (see Figure 9a). The resource nodes with a larger demand for holiday days' flow are concentrated outside the radius of $10 \mathrm{~km}$ from the county center. The lower the supply-demand ratio of tourism resources, the greater the demand (see Figure 9b). Adequate supply and demand nodes are concentrated along the Mudanjiang River, while there are problems such as shortage of supply and demand or idle resources in the county center area, eastern forestry areas and other places. On weekends or holidays, only the Jingpo Lake Scenic Area, the Bohai Kingdom Site, the Korean Folklore Experience Zone, the Agricultural Eco-Park and other resource points have relatively sufficient recreational supply capacity, while agricultural, forestry, reservoirs and other resource points can hardly meet the needs of villagers and tourists for recreation. On average, the supply-demand ratio of resource nodes in the whole region is less than 1, which indicates that their supply-demand capacity is relatively poor, while the carrying capacity of recreational resources such as scenic spots is insufficient and the vacancy rate is higher in the peak period. For county residents, the daily supply of the central county is insufficient and the attractiveness of recreational resources is relatively weak. For tourists, holiday recreation is dominated by bus transportation or self-driving. Due to the increase of road impedance during the peak period, the decrease of accessibility to resource nodes and the decrease of pressure on some recreational nodes, the carrying capacity of some recreational nodes rises; thus the 
ratio of supply and demand of resources in the peak period is comparable. The peak period did not exceed a large number, but it was still at a low level of service capacity.

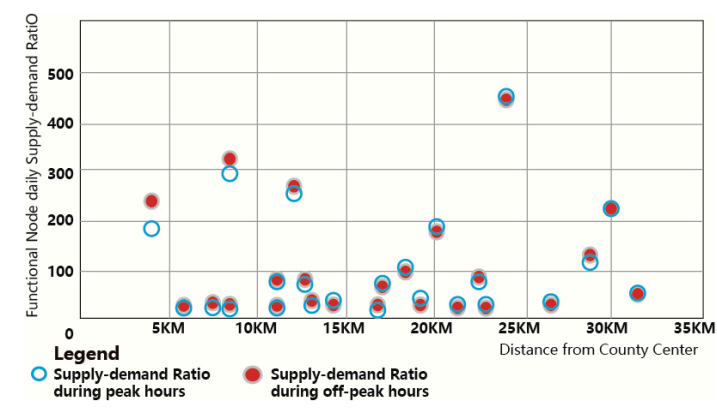

(a)

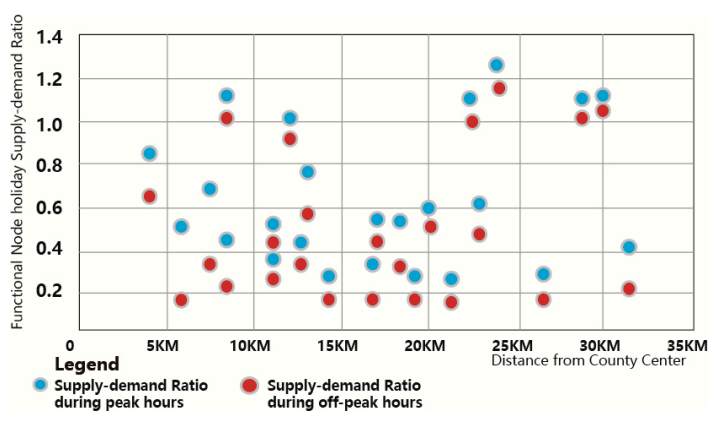

(b)

Figure 9. Supply demand ratio of resources affected by distance from county center. (a) Daily; (b) holiday.

\subsubsection{Greenway Network Planning Strategy under Flow Structure Reconfiguration}

According to the results of flow measurement, the Ning'an greenway network is still in the preliminary stage of structural development. The coordination level and the low use of various resources result in the limitation of its functional composition and resource co-ordination. The high differential distribution of flow caused by the insufficient allocation and linkage of ecology, life and production factors leads to difficulty in balancing the supply and demand of resources, thus affecting the optimization and upgrading of the whole county landscape pattern and resource construction. Furthermore, the integration of ecology, production and life requires the Ning'an network to focus on green, residential and industrial patches in the reconstruction of the process structure. Therefore, the overall planning of all grades of the structure is conducive to the complex generation and diversified development of the network with the goal of whole resource collaborative flow allocation.

(1) Reconfiguration strategies for network structure

- Four-core leading mode of internal and external flow

The county center area and the Jingbo Lake Scenic Area are two important flow points in the network framework. Although the polarization of "two cores" is obvious, the network connection between them is still in a sluggish state, forming a "dumbbell" structure. On the other hand, the Bohai Kingdom Site and the Huashuchuan Reservoir have embodied the potential of becoming a "new core access point" of regional network flow due to aspects of geographical location, passenger flow support, landscape and industrial connection already present. Therefore, the opportunity to form a "four-core" development model exists, in order to balance the flow distribution of the primary structure and lead the core agglomeration and coordinated development of the whole region. Through the coordination of key villages and towns, residential areas, the agroforestry industry, the traffic structure and the spatial development direction, the "four-core" flow rate is strengthened and the radiation range of corridors is raised (see Figure 10a). The external areas of the "four cores" drive the external flow of the network to improve with the linkage development of circles, weaken the administrative boundary, strengthen the flow connection and resource sharing and form the flow connection expansion area. Within the North-South core belt, an overall balanced and integrated resource development pattern is realized by way of ecological, landscape, economic and infrastructure flow integration.

- Secondary stability mode of functional flow blending

At present, the landscape pattern of Ning'an is heterogeneous. Smaller flow is distributed in the large forestland, in the mountainous area and in similar areas. The development level of the secondary resources outside the "four cores" is relatively low and has a slow development speed. Therefore, 
more "new potential points" with high centrality and a low supply-demand ratio should be gathered in the reconstruction of secondary circles to achieve a stable flow distribution mode by combining similar functions and natures of the resource nodes (see Figure 10b). Through "ecology + recreation, humanities + recreation, industry + recreation" and other chain-in modes, resource reorganization and agglomeration are formed in the connection of elements. The secondary network has been improved in the aspects of the integrity of the ecological landscape pattern, the protection of human resources, the sustainability of industrial economy and the high utilization rate of leisure resources.

- Edge linkage mode of the characteristic functional flow

Third-grade network resources are relatively scattered, highly eco-sensitive and relatively weak in infrastructure. However, they still have the potential to spread residential, ecological, humanistic and industrial functions. According to the distribution characteristics of resource centrality and the supply-demand ratio, the reconstruction elements are divided into four categories (see Figure 10c): (1) Residential-driven elements. Medium and high flow residential areas on the edge are included in the network reconstruction. (2) The reconstruction of ecological agglomeration elements is based on the high-function flow of ecological resources as the core, with many low-function flow nodes gathered. It is represented by the "triangle" composed of the Jingpo Lake scenic area, the mountain forest area and the human resources protection area in the south. (3) The humanistic conservation type aims at the human resources with a low function flow and weak resource utilization and protection. It combines the landscape and recreation functions brought by the greenway network to enhance the protection and utilization of resources, and forms the expansion and value-added of the flow with humanistic characteristics. (4) The industrial upgrading type combines non-key industrial resources with the greenway. On the one hand, it provides recreational places for the surrounding residents, while on the other hand, it provides opportunities for non-key industries to enhance efficiency and realize mutual benefits and a win-win between the industry and the greenway, especially in the process of resource combination between industrial resources on both sides of the traffic axis and the greenway belt connection.

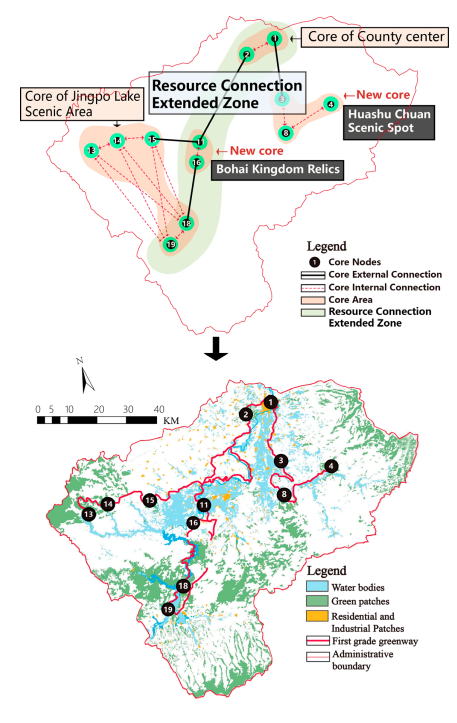

(a)

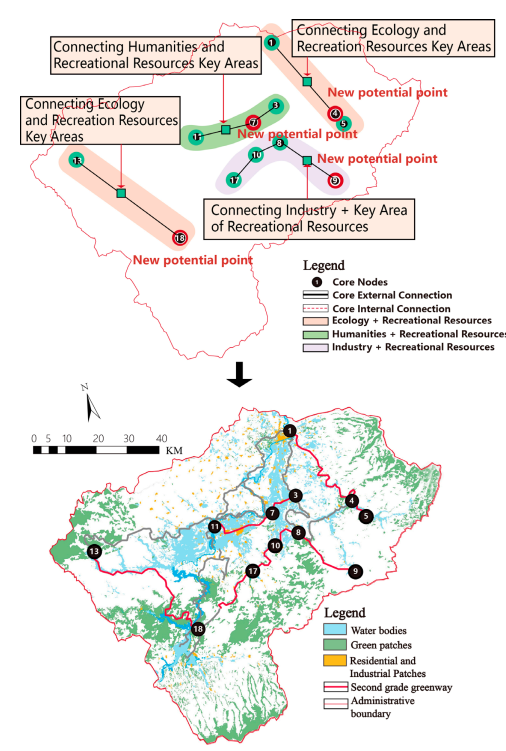

(b)

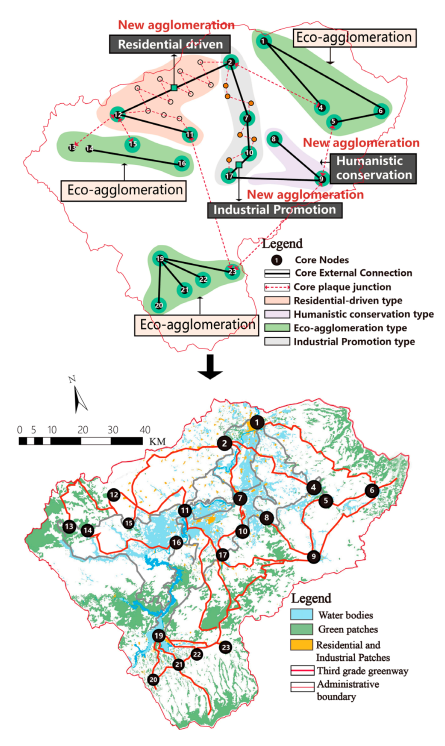

(c)

Figure 10. Graded generation of corridor structure. (a) First grade; (b) second grade; (c) third grade.

(2) The Strategy of Network Multivariate Value Promotion

- Diversified development of ecological value. 
Combining natural scenic resources such as Jingpo Lake, Xiaobeihu Lake and Huashuchuan Reservoir, a multi-core collaborative model of "Greenway Network + Whole-region Scenic Area Resources" is formed to achieve a balance of social, ecological and economic benefits from the balance of flow supply and demand: (1) Promoting ecological benefits and returning to the nature of ecology. A great increase in green elements in pedestrian scenic spots, building a green vitality and relaxation rhythm of the changing recreational space. (2) Strengthening the traffic connection ability of scenic spots by the mode of a "three-in-one" scenic spots tourism special line, village bus line and greenway recreational line, and linking the greenway with important traffic hubs to improve the convenience of scenic spots and the richness of the experience content.

- Cultural system of mutual promotion of resources.

Balancing the supply-demand ratio by means of mutual promotion of resources not only comprises the protection of the county cultural system, but is also the driving force of a balanced development of the region-wide resources: (1) Promoting the blending the space between historical culture and green resources. This can not only solve the disorderly outward diffusion of cities and towns, but also avoid the conflict with the surrounding environment's construction. (2) Fully excavate historical routes. Taking the cultural development of different regions as the backbone, the cultural heritage sites can form a heritage corridor representing the cultural heritage of different regions, from the Bohai Kingdom Site to the Yinggeling Culture Site. (3) Cultural display experience. Utilize the material or intangible cultural heritage resources along the greenway, encourage the development of a cultural experience with Manchu characteristics, and explore the traditional culture and art of ethnic minorities in the Ning'an area.

- Promoting network economy by recreational industry

In the early stage of the greenway network development, there is a need to balance multiple interests. Taking rich tourism resources as a development basis of the compound greenway, while considering the ecological benefits and the interests of residents in villages and towns, is conducive to the multi-value development of the resources. It can be fed back by the economic benefits in the middle and later period: (1) Tourism convenience and economic benefits are optimized by promoting the development of "greenway tourism + Internet" and "greenway tourism + sports". It can balance the fluctuation of economic income caused by the difference during the peak period of tourism flow. (2) Economic benefits and industrial value are promoted by the mode of "Greenway Network + modern agricultural experience" promoted in combination with the Ning'an Industrial Park. It takes "the integration of agriculture and tourism, culture and tourism, and forestry and tourism" as the starting point, and comprehensively promotes the integration development of all industries in the whole region through the strategy of "one industry-driven, multi-industry simultaneous development".

\section{Conclusions and Implications}

Although more and more counties are building multi-functional greenways with the development and popularity of the healthy environment, one of the major reasons why the quality and utilization rate of greenways have not been improved in China is the lack of planning methods for effective resource organization [58]. Therefore, the current study attempted to identify the important dimensions of improving resource inter-relations, further leading to the harmony of the overall green space. Additionally, the study verified that there are differences in corridor flow caused by different resource combinations. The current study is unique, because the gravity-resistance model was generated and used to measure the functional flow of corridors and nodes, contributing to a more efficient integration of multi-functional resources in the greenway context.

First, the multi-value of resources is integrated into the concept of the network and the traditional single line space of the greenway is broken in the process of connecting resources in a series. Specifically, the multi-functional greenway integrates the functions of ecology, recreation, culture, society, aesthetics 
and economy [59]. We summarized the identification of resources from the perspective of pluralism, which it possible for the greenway to realize the concordance of resources development along the corridors step-by-step and to form a multi-value network. Natural resources, cultural resources and economic resources have been strengthened in the process of identification and utilization. At the same time, the networking potential of natural, cultural and industrial resources was utilized especially in the counties with abundant tourism resources, where additional economic value can be harvested in the form of a regional network. Taking the whole county's ecological value protection as the core, the greenway network targets boosting a single value of ecology, recreation or landscape, as well as coupling multiple values. It combines all types of important resource nodes of ecology, life and production to form a networked function flow covering the whole public space.

Second, the study stresses the research of the building and application of a gravitation-resistance model, indicating the relationship between identified resources by using the network flow analysis method. The multiple demands of the Ning'an greenway network construction are analyzed. The greenway network has been seen as the process of organizing resource points and resource corridors into a network in the green space structure. From the perspective of multi-component resources, a network system composed of linear and patchy resources has been formed, by integrating industrial resources, infrastructure resources and leisure tourism resources. The centrality and the supply-demand ratio of nodes were quantitatively analyzed according to the flow distribution. The ecological value, humanistic value and economic value of the network were excavated intuitively by the mutual attraction of the elements. The result implies that the high-function flow corridors are relatively concentrated in the county center and main scenic spots due to the impact of the artificial environment. In villages and surrounding areas with better ecological conditions, high-function flow corridors are scattered. At the same time, peak hours and off-peak hours and age differences have a greater impact on functional flow differences. Therefore, from the perspective of flow distribution balance, it is necessary to improve the accessibility of the network and the convenience for the elderly to reach recreational resources in the structural reconstruction. At the same time, the "new core access points" of the network are the resource nodes with high flow and centrality. In the reconstruction of a network circle layer, resource nodes with high centrality and supply-demand ratios are gathered to form a stable distribution, so as to improve the utilization efficiency of various resources. In a relatively low-level network, combining different functional features to connect and combine resources can promote the flow balance and value improvement of a greenway more than using resources alone.

Constructed this way, the network has a more comprehensive nature and is able to highlight the ecological value, cultural value and economic value of resources. After measuring and analyzing the network structure, development strategies of network structure optimization and value promotion are put forward. At the same time, the simple operation mode and moderate data demand make the model universally practical and operable for county areas. It is more scientific and convenient to analyze the greenway structure and lay a foundation for the construction and implementation of the greenway network in county areas.

Note: the pictures were drawn by the authors.

Author Contributions: Conceptualization, T.Z.; Data curation, X.J. and T.Z.; Funding acquisition, T.Z.; Investigation, X.J.; Methodology, X.J.; Project administration, T.Z.; Resources, T.Z.; Software, X.J.; Supervision, T.Z.; Validation, X.J.; Visualization, X.J.; Writing—original draft, X.J.; Writing—review and editing, X.J. and T.Z. All authors have read and agreed to the published version of the manuscript.

Funding: This research was funded by National Key RED Program of China: Low-carbon planning and design of county-territory towns based on the inheritance of regional characteristics, grant number 2018YFC0704705.

Conflicts of Interest: The authors declare no conflict of interest.

\section{References}

1. Baschak, L.A.; Brown, R.D. An ecological framework for the planning, design and management of urban river greenways. Landsc. Urban Plan. 1995, 33, 211-225. [CrossRef] 
2. Gobster, P.H.; Westphal, L.M. The human dimensions of urban greenways: Planning for recreation and related experiences. Landsc. Urban Plan. 2004, 68, 147-165. [CrossRef]

3. Coutts, C.; Chapin, T.; Horner, M.; Taylor, C. County-level effects of green space access on physical activity. J. Phys. Act. Health 2013, 10, 232-240. [CrossRef] [PubMed]

4. Little, C.E. Greenways for America; Johns Hopkins University Press: Baltimore, MD, USA, 1995; p. 288.

5. Ahern, J. Greenways as a planning strategy. Landsc. Urban Plan. 1995, 33, 131-155. [CrossRef]

6. Grossman, G.; Krueger, A. Economic Growth and the Environment. Q. J. ECON. 1995, 110, $353-377$. [CrossRef]

7. Ashley, C.; Xiang, W.N.; Jeff, Y.; David, W. Planning for multi-purpose greenways in Concord, North Carolina. Landsc. Urban Plan. 2004, 68. [CrossRef]

8. Teng, M.J.; Wu, C.G.; Zhou, Z.X.; Elizabeth, L.; Zheng, Z.M. Multipurpose greenway planning for changing cities: A framework integrating priorities and a least-cost path mode. Landsc. Urban Plan. 2011, 103. [CrossRef]

9. Chen, X.H.; Zhou, H.H.; Wang, X. The vulnerability and coordination of the coupling of environment, economy and society in county: A case of Qiqihar city of Heilongjiang province. Hum. Geogr. 2018, 33, 94-101.

10. Xu, X.; Jiang, Q.Z.; Hua, W.; Me, G.P.; Song, C.B. Green route selection in county territory. Planners 2016, 32, 170-175.

11. Yi, B.; Wei, L.Y. On the construction of ecological network of county green space based on ecological level. Land. Arch. 2015, 44-52.

12. Liu, B.Y. The strategic role of greenway in the future development of urban ecological and cultural core areas in China. Chin. Land. Arch. 2012, 28, 5-11.

13. Cook, E.A. Landscape structure indices for assessing urban ecological networks. Landsc. Urban Plan. 2002, 58, 269-280. [CrossRef]

14. Dong, J.J.; Zhang, X.W. Study on compound greenway planning: Qitai greenway planning example. Planners 2015, 31, 194-198.

15. Zhang, G.J.; Ma, H.J.; Li, H.M. Studies on the construction of compound greenway network of culture and ecology for the old city area in Xi'an. J. Xi'an Univ. Arch. Tech. 2017. [CrossRef]

16. Chin, E.Y.; Kupfer, J.A. Prevalence of ecological, environmental, and societal objectives in urban greenway master plans. Southeast. Geogr. 2019, 59, 153-171. [CrossRef]

17. Zhu, Q.; Liu, H.L. Review on the research progress of green channel planning. Urban Probls. 2006, 5, 11-16.

18. Liu, B.Y.; Xu, W.H. Strategic plan of greenway construction in ecological Zhejiang. J. Chin. Urban Forest. 2004, 2, 14-18.

19. Yao, P.; Sun, Y.H.; Xi, Q.H.; Li, F.Z. Research on ecological scenic byways planning coupled with multiple values-Taking Ulanqab four horizontal traffic belt as an example. Chin. Land. Arch. 2019, 35, 101-106.

20. Lin, P.Y.; Liaw, S.C. Applying the fuzzy Delphi method to analyze the greenway functions of lover river in Kaohsiung City. J. Exp. For. Natl. Taiwan Univ. 2008, 2, 89.

21. Yang, M.; Shi, H.C.; Xu, W. A Research on waterfront greenways route selection in Wuhan East Lake based on the GIS technology. Arch. Cult. 2015, 8, 174.

22. Zhang, Y.W.; Jin, Y.F. Study on urban land function composite model based on green space optimization. Chin. Land. Arch. 2016, 32, 98-102.

23. Walmsley, A. Greenways and the making of urban form. Landsc. Urban Plan. 1995, 33. [CrossRef]

24. Pourjafar, M.; Moradi, A. Explaining design dimensions of ecological greenways. J. Ecol. 2015, 5, 66-79. [CrossRef]

25. Pinto, N.; Keitt, T.H. Beyond the least-cost path: Evaluating corridor redundancy using a graph-theoretic approach. Land. Ecol. 2009, 24, 253-266. [CrossRef]

26. Sang, J.; Liu, P. Implementation mechanism of greenway network plan based on its spatial futures. Chin. Land. Arch. 2016, 32, 108-112.

27. Dai, W. Planning rural greenway: Resource evaluation and network analysis. Open House Int. 2017, 42, 98-102.

28. Teng, M.J.; Zhou, Z.X.; Wang, P.C.; Xu, Y.R.; Wu, C.G. Landscape centrality and its applications in ecological network planning and management. Chin. J. Appl. Ecol. 2010, 21, 863.

29. Ervin, H.Z. Greenways and the US National Park system. Landsc. Urban Plan. 1995, 33, 17-25. 
30. Quattrone, M.; Tomaselli, G.; Riguccio, L.; Russo, P. Assessment of the territorial suitability for the creation of the greenways networks: Methodological application in the Sicilian landscape context. J. Agric. Eng. 2017. [CrossRef]

31. Xin, S.; Li, J.F. Evaluation and optimization of urban greenway network planning based on the landscape ecological index-A case study of Chao Zhou City. J. Green Sci. Technol. 2016, 14, 214.

32. Horta, M.B.; Bhakti, T.; Cordeiro, P.F.; Carvalho-Ribeiro, S.M.; Fernandes, G.W.; Goulart, F.F. Functional connectivity in urban landscapes promoted by Ramphastos toco (Toco Toucan) and its implications for policy making. Urban Ecosyst. 2018, 21, 1097. [CrossRef]

33. Ramani, S.E.; Kumaravel, P.; Rajamanickam, G.V. Landslide susceptibility mapping using remotely sensed data through conditional probability analysis using seed cell and point sampling techniques. J. Ind. Soc. Remote Sens. 2012, 40, 669. [CrossRef]

34. Xiao, H.; Liu, Y.; Yu, Z.; Zhang, Q.; Zhang, X. Combination of ecoprofile and least-cost model for eco-network planning. Chin. Geogr. Sci. 2014, 24, 113. [CrossRef]

35. Cohen, Y.; Amit, C.I.; Cohen, A.; Shoshani, M. Least cost path for green corridors delineation in metropolitan margins: The distance weighting effects. J. Spat. Sci. 2009, 54, 63. [CrossRef]

36. Huang, X.F.; Wu, C.F.; You, H.Y.; Xiao, W.; Zhong, S.Q. Construction of rural landscape ecological corridor in water network plain area based on MCR Model. Trans. Chin. Soc. Agric. Eng. 2019, 35, $243-251$.

37. Zhao, S.; Ma, Y.; Wang, J.; You, X. Landscape pattern analysis and ecological network planning of Tianjin City. Urban For. Urban Green. 2019, 46. [CrossRef]

38. Hall, L.A.; Beissinger, S.R. A practical toolbox for design and analysis of landscape genetics studies. Land. Ecol. 2014, 29, 1487. [CrossRef]

39. Yuan, Z.; Zhao, M.; Liu, R.J. Construction and optimization of urban green space network based on minimum cost distance and improved gravity model. J. Shaanxi Norm. Univ. (Nat. Sci. Ed.) 2017. [CrossRef]

40. Li, J.; Qiu, R.; Xiong, L.; Xu, J. A gravity-spatial entropy model for the measurement of urban sprawl. Sci. China Earth Sci. 2016, 59, 207. [CrossRef]

41. Chen, C.D.; Wu, S.J.; Meurk, C.D.; Lv, M.Q.; Wen, Z.F.; Jiang, Y.; Chen, J.L. The impact of resistance assignment on landscape connection simulation. J. Ecol. 2015, 35, 7367-7376.

42. Liu, Y.B.; Li, B.Q.; Wang, Y.J.; Chen, L.L.; Li, X.W.; Hou, X.Y. Assessment of regional ecological connectivity of Laizhou Bay Yellow River Delta coastal zone based on ecosystem service value. J. Ecol. 2019, 1-11.

43. Liu, X.R.; Yin, H.W.; Xu, J.G.; Kong, F.H.; Hou, Y.J. Developing multi-functional and composite urban greenway network in Luoyang based on LCP. Mod. Urban Res. 2018, 01, 126-131.

44. Li, F.Z.; Liang, P.S.; Li, X.; Shang, N. The layout characteristics and evaluation index system construction of multi-scale greenway. Urban Stud. 2017, 7, 17.

45. Guo, Y.Y.; Yao, Y.Q. Sustainable development compound urban greenway route selection: A case study in Dandong. J. Liaodong Univ. (Nat. Sci.) 2016. [CrossRef]

46. Chang, H.S.; Huang, S.W.; Liu, Y.Y. A study on the evaluation of the multipurpose greenways system in an urban area. J. Plan. 2010, 59. [CrossRef]

47. Chen, J.C.; Li, T.H. Analysis on the spatial variation of ecosystem service value in China. Acta Sci. Nat. Univ. Pekin. 2019, 55, 951-960.

48. Li, H.L. Study on route planning method of greenway path system in western Sichuan plateau based on minimum accumulated resistance model-taking Kangding city as an example. Urban Dev. Stud. 2018, 25, $58-64$.

49. Hu, J.S.; Dai, F. Study on planning methods of urban greenway network in China. Chin. Land. Arch. 2013, 29, 115-118.

50. Hong, I.; Jung, W.-S.; Jo, H.-H. Gravity model explained by the radiation model on a population landscape. PLOS ONE 2019, 14, 1-13. [CrossRef]

51. Julien, C.; James, M. Landscape typology and ecological connectivity assessment to inform Greenway design. Sci. Total Environ. 2019, 651, 3241-3252.

52. Tan, K.W. A greenway network for Singapore. Landsc. Urban Plan. 2004, 1. [CrossRef]

53. Snitker, G.; Castillo, A.D.; Barton, C.M.; Aubán, J.B.; Puchol, O.G.; Pardo-Gordó, S. Patch-based survey methods for studying prehistoric human land-use in agriculturally modified landscapes: A case study from the Canal de Navarrés, eastern Spain. Quatern Int. 2018, 483, 5-22. [CrossRef] 
54. Palmisano, G.O.; Govindan, K.; Loisi, R.V.; Sasso, P.D.; Roma, R. Greenways for rural sustainable development: An integration between geographic information systems and group analytic hierarchy process. Land Use Pol. 2016, 50, 429-440. [CrossRef]

55. Jing, Q.; Xiang, W.N.; Liu, Y.F.; Meng, X.C. Incorporating landscape diversity into greenway alignment planning. Urban For. Urban Green. 2018, 35, 45-56.

56. Comber, A.; Brunsdon, C.; Green, E. Using a GIS-based network analysis to determine urban green space accessibility for different ethnic and religious groups. Landsc. Urban Plan. 2008, 86, 103-114. [CrossRef]

57. Zhang, J.K. Evaluating regional low-carbon tourism strategies using the fuzzy Delphi-Analytic network process approach. J. Clean Prod. 2017, 141, 409-419. [CrossRef]

58. Chen, X. Analysis of research on greenway planning in China. J. Chin. Urban Forest. 2018. [CrossRef]

59. Türk, E. Multi-criteria decision-making for greenways: The case of Trabzon, Turkey. Plan. Prac. Res. 2018, 33, 326-343.

(C) 2020 by the authors. Licensee MDPI, Basel, Switzerland. This article is an open access article distributed under the terms and conditions of the Creative Commons Attribution (CC BY) license (http://creativecommons.org/licenses/by/4.0/). 